\title{
A drop in the bucket Gregory A Petsko
}

Address: Rosenstiel Basic Medical Sciences Research Center, Brandeis University, Waltham, MA 02454-9110, USA. E-mail: petsko@brandeis.edu

Published: 22 July 2004

Genome Biology 2004, 5: I 12

The electronic version of this article is the complete one and can be found online at http://genomebiology.com/2004/5/8/II2

(c) 2004 BioMed Central Ltd

One hundred and fifty-one billion dollars. That's the cost to the US thus far of the war in Iraq. (I base this figure on the $\$ 126.1$ billion appropriated to date plus the additional \$25 billion requested through the end of the year, which is certain to be approved. Some other estimates of the true cost are higher - as high as $\$ 186$ billion.) That sounds like a lot of money, but it's less than $10 \%$ of the annual federal budget of almost $\$ 2$ trillion. And compared with the gross domestic product of the US, which is about $\$ 11$ trillion, it's nothing, really. A drop in the bucket, as we say here.

Still, even though it's not much money, it's instructive to think about what other things could be done with $\$ 151$ billion - and some people have. It would have paid the salaries of three million new elementary school teachers, for example. It would have fully funded all of the current global anti-hunger efforts for the next five years. It would have provided more than three million students with full four-year scholarships at typical public universities ... and so on. But these aren't really serious ideas - they're mostly proposed for comparison purposes, and to make a social or political point. I much prefer ideas that fix problems completely, or that make a colossal and permanent difference. And it's in the areas of health and science that I think such ideas can be found. Here are a few things we could do with this particular drop in the bucket.

With $\$ 151$ billion, every child in the world could be given a complete set of basic immunizations. And this could be done every year for the next 40 years. Or, with $\$ 151$ billion, all world-wide AIDS programs could be fully funded for the next 12 years. This includes the Global Fund to Fight AIDS, Tuberculosis and Malaria, a multilateral initiative created three years ago to mobilize and quickly disburse billions of dollars a year to programs proven to prevent, contain, or treat HIV. The Global Fund is running out of money and may not have enough on hand to fund any new programs until 2007, according to the latest estimates. Activists say that US President Bush, whom they blame for the shortfall, urgently needs to commit significantly more aid to the Fund - at least US $\$ 1.2$ billion next year, compared to the mere $\$ 200$ million he has requested from Congress. The $\$ 151$ billion would, of course, take care of that for the next 100 years if it were devoted solely to that Fund. Bush, it should be added, promised to put two million people on life-saving drugs when he launched the PEPFAR (President's Emergency Plan for AIDS Relief) program. This program has so far provided treatment to only roughly 20,00o people in the 14 African and Caribbean countries that are eligible to benefit from it, according to estimates from the Global AIDS Alliance. The Global Fund, on the other hand, is currently treating at least that many in Rwanda alone. The president had pledged $\$ 15$ billion over 5 years to keep his promise less than $10 \%$ of the cost of the war in Iraq thus far. Fully funding all AIDS programs for the next 12 years would go a long way towards bringing the disease under control in the developing world.

With $\$ 151$ billion, 10 foundations could be set up, each with roughly the same endowment as the Howard Hughes Medical Institute. If each foundation were required by law to spend $5 \%$ of its endowment every year, as is the case with tax-exempt foundations in the US currently, a total of $\$ 7.5$ billion per year would be spent on whatever their missions happened to be. And since each foundation would be endowed by the initial expenditure, the government - and its taxpayers - would never have to spend another penny on any of them. Imagine the impact even one such foundation could have on the arts or humanities. And I like the notion of having one of them spend its $\$ 750$ million a year endowing 250 new professorships in the life sciences at research universities across the US. Every year. Forever.

With $\$ 151$ billion, we could build, equip and fully staff 500 new genomics centers, and provide an endowment to support their operating expenses and infrastructure maintenance. That's roughly one such center at every major college and university in the country. With $\$ 151$ billion, we 
could set up 10 new universities, each with a $\$ 10$ billion endowment (approximately equal to that of Princeton University), and provide them at the same time with $\$ 5$ billion to buy land, construct buildings and hire faculty. I'd like at least one of them to focus on biomedical engineering; I don't particularly care what the others do, but law schools and business schools should be forbidden. With $\$ 151$ billion, we could fund a $\$ 20$ billion research program over the next 10 years aimed at bringing the cost of sequencing a human genome down to $\$ 1,000$ or less. During this time, the remaining $\$ 131$ billion would be invested and, assuming a reasonable rate of return, at the end of the program there would be enough money left to pay for sequencing the genome of every man, woman and child in the US.

With $\$ 151$ billion, we could invite the ten largest pharmaceutical companies plus the three largest biotech companies into a room and say to them, "OK, we know it costs you $\$ 1$ billion over 12 years to develop a drug, and that it isn't worth your while to invest that kind of money in treatments for third world diseases, which don't provide enough return to even make your investment back. So here's what we're going to do. The five biggest health problems in the third world are AIDS, tuberculosis, malaria, sleeping sickness and rotavirus. We'll help each of you select one of them, based on your expertise and interest. No more than two of you can work on the same one. We will give you $\$ 1.1$ billion each over the next twelve years for you to work on the disease you've selected, which includes money to hire new people so you don't have to stop working on the things you're doing now. If, at the end of that time, you have produced an approved drug or vaccine to treat this disease, we will pay you an additional $\$ 10$ billion in guaranteed profits so that you can make the treatment available at or below cost to the people who need it. At most, this will cost a total of $\$ 111$ billion. The remaining $\$ 40$ billion will be spent in a similar way, but the target will be multi-drug resistant Staphylococcus aureus and Streptococcus pneumoniae, the burden of which affects all nations, including our own. In this program, you will be guaranteed a very large profit if you succeed, and there will be absolutely no cost to you for trying. Who wants to be first?"

I guess some of these ideas may be unrealistic, but at least a few of them seem to me to be well worth doing. Yet if we were to propose any of them to the government, I suspect the immediate reaction would be, "That costs way too much. There isn't nearly enough money for that." Maybe the government's right. I do realize that times are hard. But still. Somehow there always seems to be enough money for another war. 